\title{
CREPIS CAPILLARIS WALLR. (COMPOSITAE, LACTUCEAE), UNA ADICIÓN A LA FLORA ADVENTICIA DE MÉXICO*
}

\author{
Jerzy Rzedowski y Graciela Calderón de RZEdowski \\ Instituto de Ecología, A.C., Centro Regional del Bajío, Apdo. postal 386 \\ 61600 Pátzcuaro, Michoacán, México
}

\section{RESUMEN}

Se registra por primera vez para México la presencia de Crepis capillaris, maleza originaria de Europa. Se le observó como ruderal e invadiendo agostaderos en la parte central del estado de Veracruz, entre 1900 y 2450 m de altitud, en condiciones de clima húmedo. Se estima que su arribo a esta área debe datar de hace no mucho más de 20 años.

Palabras clave: Crepis capillaris, maleza, México, Veracruz

\begin{abstract}
The presence of Crepis capillaris, a weed native of Europe, is reported for the first time from Mexico. It was observed as ruderal and invading pastures in the central part of the state of Veracruz, within an altitudinal belt situated between 1900 and $2450 \mathrm{~m}$, in conditions of humid climate. It is estimated that the arrival of the species to this area dates from not much more than 20 years.
\end{abstract}

Key words: adventitious, Crepis capillaris, Mexico, Veracruz, weed.

Los frecuentes viajes de los autores a la ciudad de Xalapa, Ver. han permitido el hallazgo de una maleza que al parecer no se ha catalogado todavía como miembro de la flora de nuestro país.

Se trata de Crepis capillaris Wallr., planta originaria de Europa occidental, central y meridional, donde se ha registrado como sinantrópica desde tiempos

\footnotetext{
*Trabajo realizado con apoyo económico del Instituto de Ecología, A. C. (cuenta 902-07), del Consejo Nacional de Ciencia y Tecnología y de la Comisión Nacional para el Conocimiento y Uso de la Biodiversidad.
} 
prehistóricos (Rivera Núñez y Obón de Castro, 1996). Hoy se le encuentra extendida y conocida también de Asia, de Canadá, de Estados Unidos de América (incluyendo los estados de California y de Texas), de varios países sudamericanos, de Sudáfrica, al igual que de Australia y de Nueva Zelandia.

En su continente nativo se registra como habitante de praderas y otros tipos de vegetación herbácea de afinidad mesófila. Sin embargo, suele penetrar también a céspedes de parques, así como bordes de caminos, huertos, terrenos baldíos, zanjas y paredes. En calidad de adventicia se comporta principalmente como ruderal y como invasora de agostaderos en lugares de clima fresco y húmedo. Randall (2002) la sanciona como maleza nociva y maleza ambiental en diversas regiones.

En México se le encontró particularmente abundante en los alrededores de la cabecera municipal de Las Vigas, en el estado de Veracruz, a unos $2400 \mathrm{~m}$ de altitud, donde está invadiendo parcelas de cultivo de plantas forrajeras y las que se encuentran en descanso, además de su frecuente presencia a las orillas de caminos. A lo largo de la carretera Xalapa - México se le ha observado en esta última condición desde las cercanías de la población de La Joya hasta unos $7 \mathrm{~km}$ antes de llegar a la de Perote, coincidiendo aproximadamente este tramo con el piso altitudinal del bosque de Pinus patula, entre 1900 y 2450 m s.n.m.

La carretera en cuestión es una de las dos principales vías de comunicación entre el puerto de Veracruz y el centro del país, por la que transitan numerosísimos camiones de carga. Tal circunstancia permite contemplar la eventualidad de que el propágulo de Crepis capillaris pudo haber llegado en barco a la costa de México y de allí fue llevado por las ruedas de un vehículo a la zona que resultó ser ecológicamente apropiada para el establecimiento de la especie.

Otro mecanismo, quizás más verosímil, puede haber consistido en el transporte del fruto de la maleza en calidad de impureza de las semillas de algunas plantas forrajeras que se siembran en la región.

La gran abundancia de Crepis capillaris en los alrededores de Las Vigas, así como a lo largo de algunos tramos de la carretera, sugiere el hecho de que su llegada a México no debe haber sido totalmente reciente y quizás data de hace unos 20 años. Por otro lado tampoco es probable que sea mucho más antigua, pues el área estuvo sujeta a una intensa exploración botánica entre 1965 y 1980 y aparentemente no existen registros de su presencia en aquellas fechas.

Dados sus antecedentes conocidos en el extranjero, así como su ubicación ecológica hasta ahora encontrada en nuestro país, cabe predecir que los ambientes particularmente vulnerables a la invasión de esta maleza serán los agostaderos en medio del bosque mesófilo de montaña, así como de pinares y encinares húmedos del lado de la vertiente del Golfo de México.

Crepis capillaris es una planta de morfología algo variable, con látex blanco en la mayor parte de sus órganos, anual, bianual o en ocasiones persistiendo por 


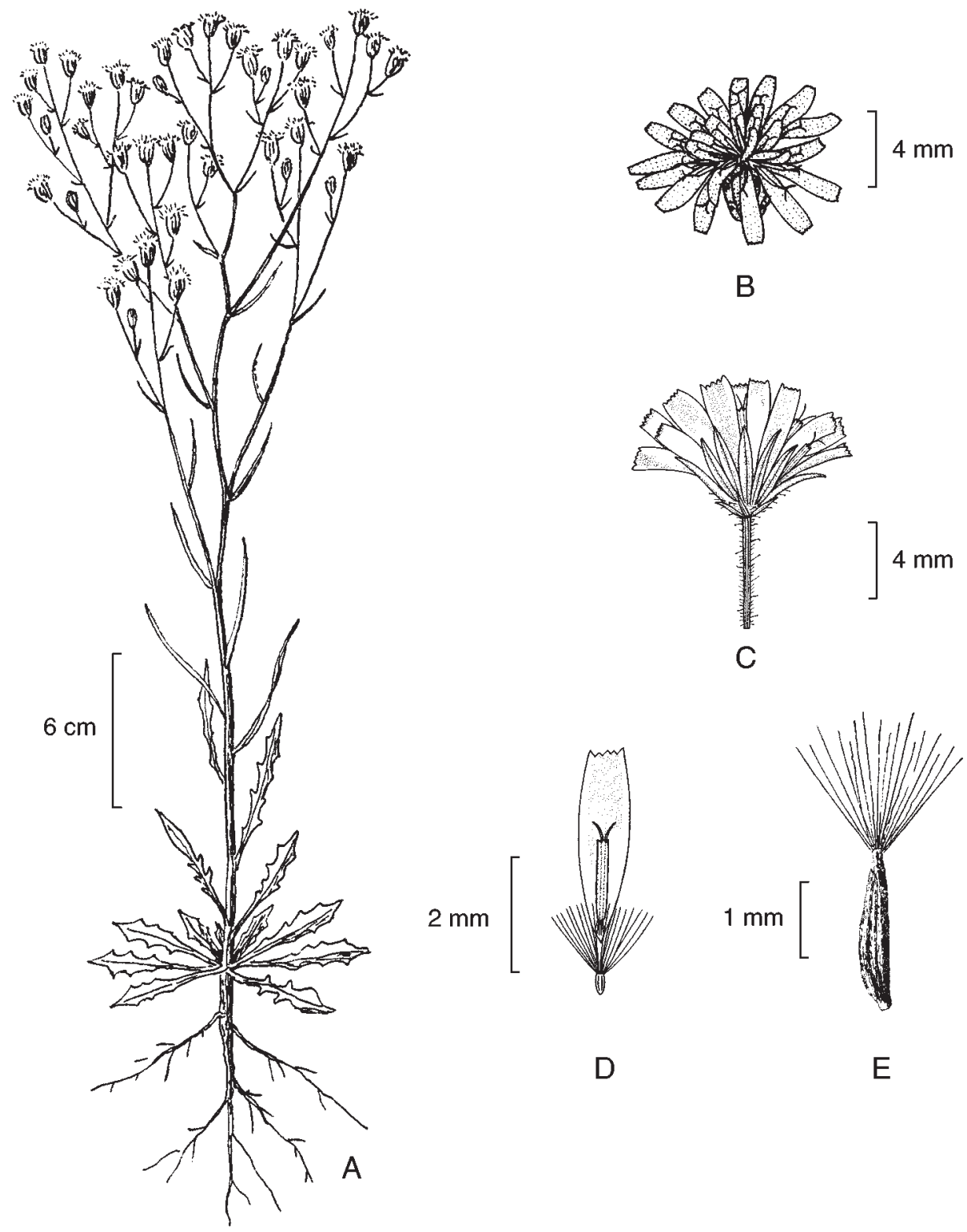

Fig. 1. Crepis capillaris. A. aspecto general de la planta; B. cabezuela vista de arriba; C. cabezuela vista de perfil; D. flor ligulada mostrando androceo, gineceo, aquenio y vilano; E. aquenio con vilano. A y E reproducidos de Buchholtz, K. P. et al. Weeds of the North Central States. North Central Regional Publication 36. Circular 718 of the University of Illinois Agricultural Experiment Station. 1960. p. 182. B, C y D ilustrados por Rogelio Cárdenas. 
un poco más de tiempo, a partir de una raíz pivotante, largamente cónica y a veces algo ramificada; de tallos erectos, con frecuencia ramificados, pubérulo-hispídulos a casi glabros, hasta de $60(90) \mathrm{cm}$ de alto, aunque por lo general de talla más modesta; sus hojas son alternas, las inferiores pecioladas, con láminas lanceoladas a oblanceoladas en contorno general, hasta de $10 \mathrm{~cm}$ de largo y $4 \mathrm{~cm}$ de ancho, esparcidamente denticuladas a profundamente runcinadas en el margen, casi glabras o algo hispídulas, las hojas caulinares son de menor tamaño, sésiles y auriculadosagitadas en la base, casi enteras a pinnatilobadas, atenuadas en el ápice; la inflorescencia tiene forma de panícula más o menos corimbiforme, que con frecuencia involucra más de la mitad del largo de la planta, sus ejes son pubérulos y a menudo provistos de pelos glandulosos oscuros mucho más largos; el involucro es cilíndrico en la floración, pero subcónico en la fructificación (carácter que es difícil de apreciar en los ejemplares de herbario), de 5 a $8 \mathrm{~mm}$ de largo, sus brácteas principales son 8 a 16, lineares, similares entre sí, además de 5 a 8 brácteas exteriores accesorias mucho más cortas, todas con pubescencia parecida a la de los pedicelos; flores individuales en número de 20 a 60, todas similares, amarilloanaranjadas, a veces teñidas un poco de rojo, hermafroditas, provistas de lígula angostamente oblonga de 3 a $6 \mathrm{~mm}$ de largo, menudamente 5-dentada en el ápice que es romo; los aquenios son fusiformes a subcilíndricos, de 1.5 a $3 \mathrm{~mm}$ de largo, amarillentos a cafés claros, con 8 a 10 costillas longitudinales, glabros o pubérulos, llevando un vilano de numerosas cerdas capilares blancas, tan largas o un poco más largas que el aquenio, fácilmente caducas.

Entre las malezas mexicanas más cercanamente relacionadas y semejantes a Crepis capillaris se encuentran Youngia japonica (L.) DC. y Lapsana communis L.

La primera (Y. japonica), frecuente en la aledaña región de Xalapa, puede distinguirse en sus involucros más pequeños (de 4 a $5 \mathrm{~mm}$ de largo) y desprovistos de pubescencia. La segunda (L. communis), que también se registra del estado de Veracruz, difiere en sus hojas basales ovadas y hasta de $6 \mathrm{~cm}$ de ancho, así como en sus aquenios más largos (de 3 a $4.5 \mathrm{~mm}$ de largo) y carentes de vilano.

Los siguientes ejemplares de herbario respaldan la presencia de esta especie en el país:

MÉXICO, Veracruz: $2 \mathrm{~km}$ al NW de La Joya, municipio de Acajete, sobre el camino a Perote. J. Rzedowski 54123 (IEB); alrededores de Las Vigas, municipio de Las Vigas, J. Rzedowski 54140 (IEB).

En el conjunto de la flora adventicia de México las Lactuceae tienen un papel importante, siendo ésta la mejor representada de todas las tribus de la familia 
Compositae. Del grupo en cuestión Rzedowski (1993) registró 14 especies sinantrópicas de procedencia extranjera a mencionar: Cichorium intybus L., Hedypnois cretica (L.) Willd., Hypochoeris glabra L., H. microcephala (Sch. Bip.) Cabrera, Lactuca serriola L., Lapsana communis L., Picris echioides L., Sonchus asper (L.) All., S. oleraceus L., S. tenerrimus L., Taraxacum officinale Weber, Tragopogon dubius Scop., T. porrifolius L., Youngia japonica (L.) DC.

Posteriormente Vibrans (1996) añadió a la lista a Hypochoeris radicata L., mientras que Calderón de Rzedowski (1997) agregó a Leontodon taraxacoides (Vill.) Mérat. De esta manera, junto con Crepis capillaris, se conocen ya para la flora de México 17 especies de malezas introducidas de Compositae, Lactuceae.

\section{LITERATURA CITADA}

Calderón de Rzedowski, G. 1997. Familia Compositae, tribu Lactuceae. Flora del Bajío y de Regiones Adyacentes. Fasc. 54. Instituto de Ecología. Pátzcuaro, Mich. 55 pp.

Randall, R. P. 2002. Crepis capillaris. In: The global compendium of weeds. Disponible en: http://www.hear.org/gcw/index.html.

Rivera Núñez, D. y C. Obón de Castro. 1996. Paleoethnobotany of Compositae in Europe, North Africa and the Near East. In: Compositae: Biology \& utilization. Proceedings of the International Compositae Conference, Kew 1994. The Royal Botanic Gardens. Kew. Vol. 2. pp. 517-545.

Rzedowski, J. 1993. El papel de la familia Compositae en la flora sinantrópica de México. Fragm. Flor. Geobot. Suppl. 2(1): 123-138.

Vibrans, H. 1996. Notes on neophytes 2. New records for Asteraceae from the center of Mexico. Phytologia 81(5): 369-381. 